УДК 615.322:615.07:543.544

\title{
РАЗРАБОТКА И ВАЛИДАЦИЯ МЕТОДИКИ ИДЕНТИФИКАЦИИ КАЛЕНДУЛОЗИДОВ В НАСТОЙКЕ КАЛЕНДУЛЫ. СООБЩЕНИЕ 2.
}

\author{
() Е.А. Хохлова", А.А. Здорик, В.А. Георгияни, Л.И. Вишневская \\ Национальный фрармацевтический университет, Пушкинская, 53, Харьков, \\ 61002 (Украина), e-mail: kateryna_khokhlova@ukr.net
}

Разработана методика идентификации календулозидов настойки календулы методом тонкослойной хроматографии. Изучены ее валидационные характеристики - специфичность, робастность, прецизионность. При изучении робастности исследовано влияние типа камеры, стационарной фазы, расстояния для хроматографирования, условий высушивания, стабильность испытуемого раствора во время анализа, определены оптимальные условия хроматографирования. Доказана специфичность определения календулозидов настойки календулы в сравнении с раствором сравнения календулозидов. Изучены прецизионность методики на одной и на разных пластинах, внутрилабораторная прецизионность. Доказана возможность использования методики для стандартизации настойки календулы в условиях лабораторий по контролю качества. Для обеспечения специфичности идентификации настойки календулы также целесообразным является определение характерных для цветков календулы веществ - флавоноидов.

Ключевые слова: Calendula officinalis L., настойка календулы, календулозиды, тонкослойная хроматография, валидация.

\section{Введение}

Настойка календулы - лекарственное растительное средство, которое широко применяется в медицинской практике. Препарат используется как антисептик, имеет дезинфицирующее местное действие при нагноении ран, ожогах кожи, порезах, при воспалении слизистых оболочек полости рта, миндалин глотки, при стоматите и гингивите. Настойка календулы используется также как желчегонное средство при холангитах, дискинезиях желчевыводящих путей, холециститах [1].

Контроль качества лекарственного растительного сырья (ЛРС) и лекарственных растительных препаратов (ЛРП), которые содержат комплекс биологически активных веществ (БАВ), является сложной аналитической задачей. При стандартизации ЛРС и ЛРП широко используется метод тонкослойной хроматографии (ТСХ) [2-4]. Согласно требованиям Государственной фармакопеи Украины (ГФУ), которая гармонизирована с Европейской фармакопеей (ЕФ), для методик идентификации методом ТСХ должны быть изучены валидационные характеристики, такие как специфичность, робастность (на стадии разработки) и прецизионность [2].

Целью настоящей работы была разработка и валидация методики идентификации календулозидов

Хохлова Екатерина Александровна - ассистент кафедры аптечной технологии лекарств им. Д.П. Сала, кандидат фармацевтических наук, тел. +38(057) 706-35-81, e-mail: kateryna_khokhlova@ukr.net.

Здорик Александр Анатольевич - доцент кафедры фармацевтической химии, кандидат фармацевтических наук, e-mail: oleksandr_zdoryk@ukr.net

Георгияни Виктория Акоповна - заведующая кафедрой фармацевтической химии, доктор фармацевтических наук, професcop, e-mail: vgeor@ukr.net

Вишневская Лилия Ивановна - заведующая кафедрой аптечной технологии лекарств им. Д.П. Сала, доктор фармацевтических наук, профессор,

e-mail: lilya-vishn@ rambler.ru настойки календулы методом тонкослойной хроматографии (ТCX). При проведении валидации планировали свой эксперимент, учитывая практические примеры определения валидационных характеристик, описанные в публикациях [3-6].

\section{Экспериментальная часть}

Объект исследования - настойка календулы, производитель Агрофирма Ян, Украина, сер. № 20412, 60911, 71211. Исходное сырье - цветки ноготков лекарственных (Calendula officinalis L.).

\footnotetext{
* Автор, с которым следует вести переписку.
} 
Для идентификации был использован метод ТСХ. Хроматографирование проводили в соответствии с требованиями ГФУ [2].

Стационарная фаза. ТCX-пластинки на силикагеле: Macherey-Nagel (DC-Fertigfolien ALUGRAM Sil $\mathrm{G} / \mathrm{UV}_{254}$, Германиия, сер. 006161, подложка - алюминий), Merck (Silica gel $60 \mathrm{~F}_{254}$, Германия, сер. 1.05729, подложка - стекло).

Подвижная фаза. Хлороформ Р - метанол Р - вода Р (65 : 35 : 8).

Испытуемый раствор. 25 мл препарата помещали в выпарительную чашку, упаривали на водяной бане до объема около 5 мл, охлаждали, фильтровали через бумажный фильтр. Фильтр с осадком помещали в стакан на 50 мл, прибавляли 5 мл 96\%-ного этанола Р и перемешивали до растворения осадка. Раствор сливали во флакон на 10 мл.

Раствор сравнения. Раствор стандартного образца календулозидов (ГФУ, сер. 1). Приготовление раствора сравнения. К 5,0 г календулозидов прибавляли 5 мл метанола $P$, перемешивали, выдерживали и использовали надосадочную жидкость.

Нанесение образцов. Наносили испытуемый раствор полосами, используя микрошприц (Наmilton Bonaduz AG, Switzerland, MB-29-11-1), в объеме 10 мкл; раствор сравнения календулозидов - в объеме 10 мкл.

Tuп и конфигурация хроматографической камеры. Использовали камеру с разделительным выступом на дне ((Сорбфил, Россия $(19 \times 19,5 \times 6,5))$ и камеру с плоским дном (Latch-LID Chromatotanks, CША $(27 \times 7 \times 26))$. Насыщение хроматографической камеры проводили согласно требованиям ГФУ [2].

Расстояние для хроматографирования -8 и $10 \mathrm{cм.}$

Высушивание и дериватизация. После элюирования и высушивания пластинки в течение 30 мин опрыскивали пластинку с помощью химического проявителя. Как проявитель использовали реактив серной кислоты [5].

Высушивание пластинки после дериватизации проводили в сушильном шкафу при температуре $100{ }^{\circ} \mathrm{C}$ в течение 5 мин. Изучали стабильность результата хроматографирования в течение 1 часа. Оценивали результат хроматографирования, просматривая пластинку при дневном свете, сравнивая коэффициент удерживания $\left(R_{f}\right)$, цвет и форму выявившихся зон на хроматограмме испытуемого раствора и хроматограмме раствора сравнения.

Документирование. Для документирования хроматограмм после их проявления были использованы фотографические снимки.

Температура и влажность. Для получения воспроизводимых результатов проводили эксперимент при температуре воздуха не более $25^{\circ} \mathrm{C}$, относительной влажности воздуха - не более $75 \%[5,6]$.

Результаты. На хроматограмме испытуемого раствора должны выявиться в средней части пластинки две основные четко разделенные сине-фиолетовые зоны, что соответствуют календулозидам, на хроматограмме раствора сравнения. На хроматограмме допускается наличие других зон.

Изучали валидационные характеристики методики идентификации календулозидов настойки календулы - робастность, специфичность и прецизионность.

При изучении робастности исследовали стабильность испытуемого раствора во время анализа, влияние типа камеры и стационарной фазы, расстояния для хроматографирования, условий высушивания. Изучение специфичности определения календулозидов настойки календулы проводили, сравнивая хроматограмммы испытуемого образца настойки календулы и раствора сравнения календулозидов. В ходе изучения прецизионности была исследована прецизионность на одной и на разных пластинках, внутрилабораторная прецизионность [3-6].

\section{Обсуждение результатов}

На рисунке 1 приведены результаты исследования стабильности испытуемого образца на пластинке до хроматографирования.

Как следует из результатов, приведенных на рисунке 1, между индивидуальными зонами образцов не наблюдается отличий по цвету, интенсивности, форме, выявленные зоны размещены параллельно, что свидетельствует о стабильности испытуемого образца настойки календулы на пластинке в течение 3 ч.

Стабильность результатов дериватизации. Результаты изучения стабильности хроматографического результата после дериватизации в течение 1 ч - сразу после проявления и через 5, 10, 30 и 60 мин приведены на рисунке 2. 
Как следует из рисунка 2, оценивать результат хроматографирования целесообразно в течение первых 10 мин высушивания после дериватизации, когда цвет и четкость выявленных зон наиболее интенсивны.

Влияние стационарной фазы. Результаты хроматографирования календулозидов настойки календулы на различных типах и марках стационарной фазы «Macherey-Nagel» (алюминиевая подложка), «Merck» (стеклянная подложка) и изменение значений $R_{f}$ для зон, что выявляются на уровне раствора сравнения календулозидов, приведены на рисунке 3 .

Полученные результаты показывают, что сине-фиолетовые зоны, соответствующие календулозидам А и $\mathrm{B}$, выявляются в средней части хроматограмм с $R_{f}=0,45$ и 0,55 для пластинок «Macherey-Nagel» и с $R_{f}=0,49$ и 0,59 для пластинок «Merck» соответственно. Разница в значении $R_{f}$ для зон календулозидов А и В составляет 0,05. Таким образом, обе марки ТСХпластин могут быть использованы при проведении идентификации календулозидов настойки календулы по вышеописанной методике.

Влияние расстояния для хроматографирования. Результаты хроматографирования, полученные при прохождении подвижной фазы по слою сорбента 8 и 10 см, приведены на рисунке 4.

Установлено, что при увеличении длины пробега подвижной фазы разделительная способность компонентов настойки не повышается, а время хроматографирования увеличивается и составляет для 8 см - 44 мин, для 10 см - 53 мин. Таким образом, оптимальный пробег подвижной фазы по слою сорбента -8 см.

Влияние типа камеры. Изучения влияния камеры с разделительным выступом на дне и с плоским дном на результаты хроматографирования приведены на рисунке 5 .

Как следует из рисунка 5 , конфигурация хроматографической камеры не влияет на хроматографический результат. При проведении эксперимента могут быть использованы обе камеры.

Спеиифичность. По данным литературы календулозиды являются специфичными БАВ для цветков календулы $[7,8]$. Использование в качестве растворителя 70\%-ного этанола обеспечивает экстрагирование календулозидов в настойку и позволяет использовать данную группу веществ при контроле качества готового продукта.
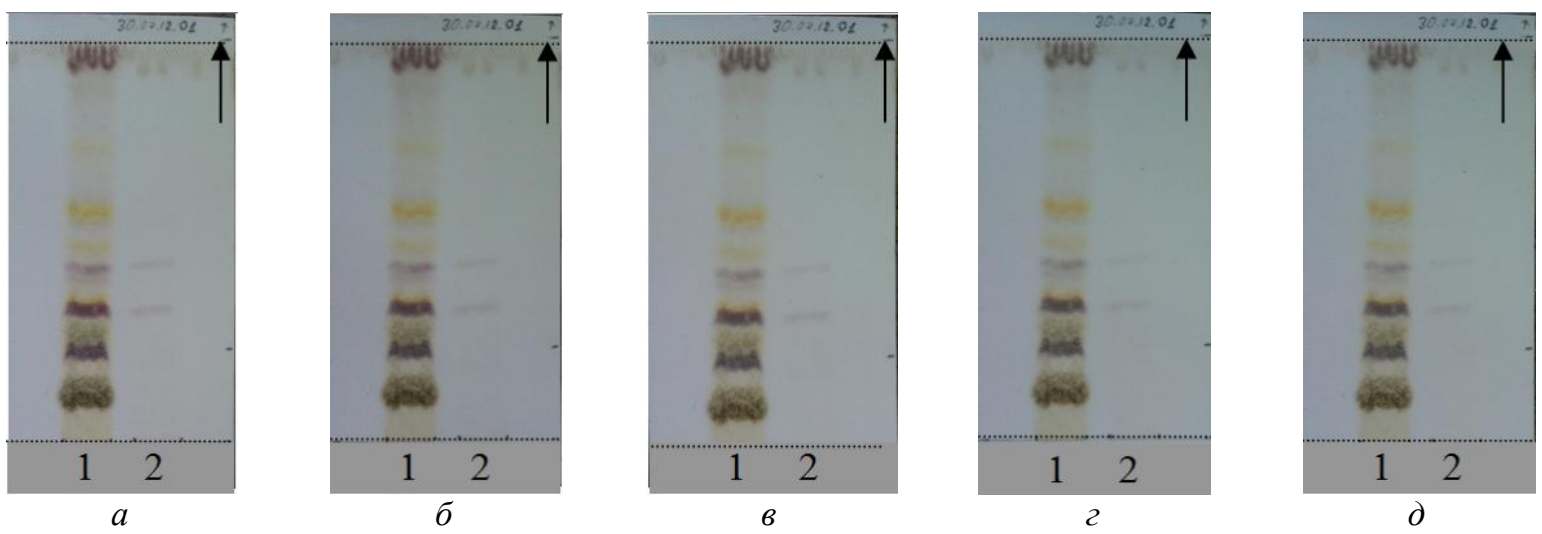

Рис. 2. Стабильность хроматографического результата во времени, дневной свет; $a$ - сразу, горячая пластинка; $\sigma$ - 5 мин; в - 10 мин; 2 - 30 мин; $\partial$ - 60 мин: 1 - испытуемый раствор настойки календулы; 2 - раствор сравнения календулозидов 

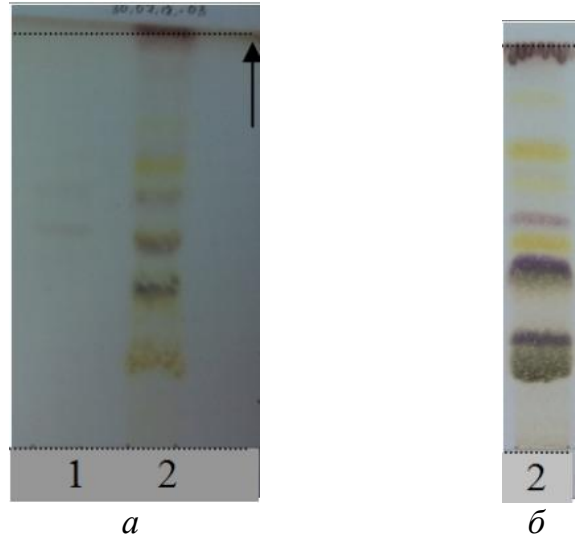

Рис. 3. Влияние стационарной фазы на хроматографический результат, дневной свет; $a$ - Silica Gel 60F 254 (Merck); $\sigma$ - Alugram Sil $\mathrm{G} / \mathrm{UV}_{254}$ (Macherey-Nagel): 1 - раствор сравнения календулозидов; 2 - испытуемый раствор настойки календулы
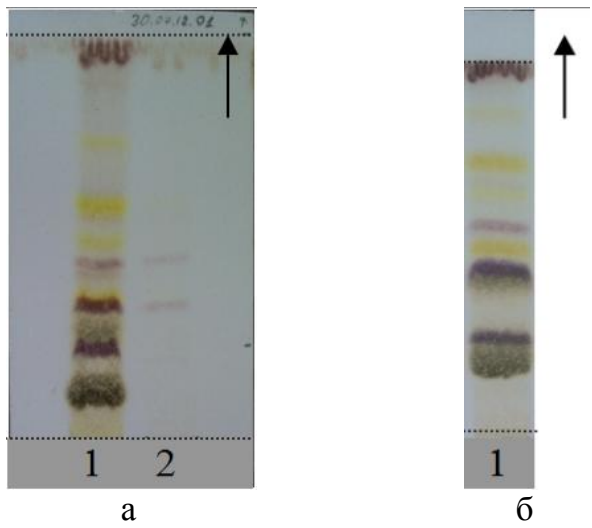

Рис. 5. Влияние типа камеры, дневной свет; $a$-камера с дном с двумя желобами; $\sigma$-камера с плоским дном: 1 - испытуемый раствор настойки календулы; 2 - раствор сравнения календулозидов

тельно их количества, интенсивности окрашивания, размещены параллельно и четко разделены.

\section{Bbыводbl}

Разработана методика идентификации календулозидов в настойке календулы методом ТСХ. Определены валидационные характеристики методики - специфичность, робастность, прецизионность. Методика может быть использована для контроля качества настойки календулы.

\section{Список литературы}

1. Государственный реестр лекарственных средств Украины по состоянию на 08.04.2014 г. Киев, 2014. [Электронный ресурc]. URL: http://www.drlz.kiev.ua.

2. Государственная фармакопея Украины. Харьков, 2008. 1-е изд. Доп. 2. 620 с.

Рис. 4. Влияние длины пробега подвижной фазы, дневной свет; $a-8$ см; $\sigma-10$ см: 1 - испытуемый раствор настойки календулы; 2 - раствор сравнения календулозидов

Использование в качестве раствора сравнения стандартного образца календулозидов, нанесенного параллельно с испытуемым раствором на одну и ту же пластинку, обеспечивает максимальную объективность результата. Как следует из рисунка 2, на хроматограмме испытуемого раствора настойки календулы выявились две четко разделенные зоны сине-фиолетового цвета на уровне соответствующих зон на хроматограмме раствора сравнения (календулозиды). Таким образом, идентификация календулозидов в настойке календулы методом ТCX по разработанной методике, а также характерного хроматографического профиля флавоноидов $[7,8]$, обеспечивает специфичность определения готового продукта.

Результаты, полученные при определении прецизионности, показали, что зоны, соответствующие календулозидам, выявленные на исследованных хроматограммах, были идентичны относи- 
3. Хохлова Е.А., Вишневська Л.И., Гарна С.В., Котов А.Г. Разработка и валидация методики идентификации изофлавоноидов и тритерпеновых сапонинов в настойке «Атерофит-норма» методом тонкослойной хроматографии // Фармаком. 2013. №1. С. 38-51.

4. Хохлова Е.А. Разработка и стандартизация настойки «Атерофит-норма» для терапии ишемической болезни сердца : дис. ... канд. фармац. наук. Харьков, 2013. 216 с.

5. Reich E., Schibli A. High-Performance Thin-Layer Chromatography for the Analysis of Medicinal Plants. New York, 2006. 264 p.

6. Koll K., Reich E., Blatter A., Veit M. Validation of Standardized High-Performance Thin-Layer Chromatographic Methods for Quality Control and Stability Testing of Herbals // Journal of AOAC International. 2003. Vol. 86, N5. Pp. 909-915.

7. Государственная фармакопея Украины. Харьков, 2011. 1-е вид. Доп. 4.540 с.

8. Zdoryk O.A., Khokhlova K.O., Georgiyants V.A., Vyshnevska L.I. Investigation of Physical and Chemical Stability of Ointment with Herbals // International Journal of Pharmaceutical Compounding. 2014. N3. Pp. 248-252.

Поступило в редакцию 16 июня 2014 г.

После переработки 30 ноября 2014 г.

Khokhlova K.O.*, Zdoryk O.A., Georgiyants V.A., Vyshnevska L.I. DEVELOPMENT AND VALIDATION OF IDENTIFICATION METHOD OF CALENDULOSIDES IN THE MARIGOLD TINCTURE. MESSAGE 2.

National University of Pharmacy, Pushkinskaya str., 53, Kharkov, 61002 (Ukraine),

e-mail: kateryna_khokhlova@ukr.net

The thin-layer chromatography method of calendulosides' identification in the Marigold tincture was developed. The validation characteristics such as specificity, robustness, precision were studied. During robustness study the influences of chamber's type, stationary phase, development distance, conditions of dryness, stability of the test solution during analysis were investigated. The optimal conditions of chromatography analysis were investigated. The specificity of method of calendulosides' determination was proved with the reference standard of calendulosides. The precision of the method on the same and on the different plates, the interlaboratory precision were studied. The possibility of usage developed method for standardization of Marigold tincture in the condition of the quality control lab was proved. For assuring specificity of identification of Marigold tincture, the determination of characteristic substances for Marigold flower - flavonoids, is reasonable.

Keywords: Marigold tincture, calendulosides, thin-layer chromatography, validation.

\section{References}

1. Gosudarstvennyi reestr lekarstvennykh sredstv Ukrainy. [State Register of Medicinal Products of Ukraine]. 08.04.2014. Kiev, 2014. URL: http://www.drlz.kiev.ua. (in Russ.).

2. Gosudarstvennaia farmakopeia Ukrainy. [State Pharmacopoeia of Ukraine]. Kharkiv, 2008, I ed., add. 2, 620 p. (in Russ.).

3. Khokhlova E.A., Vishnevs'ka L.I., Garna S.V., Kotov A.G. Farmakom, 2013, no. 1, pp. 38-51. (in Russ.).

4. Khokhlova E.A. Razrabotka i standartizatsiia nastoiki «Aterofit-norma» dlia terapii ishemicheskoi bolezni serdtsa : dis. ... kand. farmats. nauk. [Development and standardization of infusion «Artrofit norm» for the treatment of coronary heart disease: the dissertation of the candidate of pharmaceutical sciences]. Kharkiv, 2013, 216 p. (in Russ.).

5. Reich E., Schibli A. High-Performance Thin-Layer Chromatography for the Analysis of Medicinal Plants. New York, 2006. $264 \mathrm{p}$.

6. Koll K., Reich E., Blatter A., Veit M. Journal of AOAC International, 2003, vol. 86, no. 5, pp. 909-915.

7. Gosudarstvennaia farmakopeia Ukrainy. [State Pharmacopoeia of Ukraine]. Kharkiv, 2008, I ed., add. 4, 540 p. (in Russ.).

8. Zdoryk O.A., Khokhlova K.O., Georgiyants V.A., Vyshnevska L.I. International Journal of Pharmaceutical Compounding, 2014, no. 3, pp. 248-252.

Received June 16, 2014

Revised November 30, 2014

\footnotetext{
Corresponding author.
} 
